\title{
Preparation and formation mechanism of levoglucosan from starch using a tubular furnace pyrolysis reactor
}

\author{
Zhiguang Yang ${ }^{\mathrm{a}, \mathrm{b}, *}$, Xueping Liu ${ }^{\mathrm{a}}$, Zhidong Yang ${ }^{\mathrm{c}}$, Guoqiang Zhuang ${ }^{\mathrm{b}, * *}$, Zhihui Bai ${ }^{\mathrm{b}}$, \\ Hongxun Zhang ${ }^{b}$, Yifei Guo ${ }^{a}$ \\ a Department of Environmental and Municipal Engineering, Henan University of Urban Construction, Pingdingshan 467036, China \\ ${ }^{\mathrm{b}}$ Laboratory of Environmental Biotechnology, Research Center for Eco-Environmental Sciences, Chinese Academy of Sciences, Beijing 100085, China

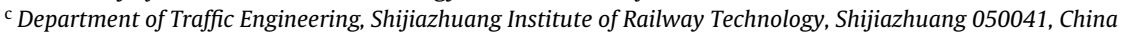

\section{A R T I C L E I N F O}

\section{Article history:}

Received 22 October 2012

Accepted 30 March 2013

Available online 10 April 2013

\section{Keywords:}

Pyrolysis

Starch

Levoglucosan

Pyrolysis mechanism

\begin{abstract}
A B S T R A C T
Tubular furnace pyrolysis reactor for the production of organic liquids from biomass has been demonstrated at a pilot-scale of $500 \mathrm{~g} / \mathrm{batch}$ of dry feed at a temperature of $360-420^{\circ} \mathrm{C}$. Treatment of starch gives high yields of 1,6-anhydro- $\beta$-D-glucopyranose (levoglucosan, LG). The yield depends on the heater temperature and the vacuum pressure in the reactor. The maximum yield of levoglucosan from corn starch is about $56 \%$ (analytical value) at ultimate pressure of $6 \times 10^{-2} \mathrm{~Pa}$, pumping speed of $15 \mathrm{~L} / \mathrm{s}$ and temperature of $390^{\circ} \mathrm{C}$. Under the same conditions, the products of levoglucosan pyrolysis are exactly the same as starch pyrolysis. Based on these experimental results and further thermal analysis, a new pyrolysis mechanism is provided and discussed.
\end{abstract}

(C) 2013 Elsevier B.V. All rights reserved.

\section{Introduction}

Necessity of developing alternative sources of energy and chemical feedstock is gaining renewed interests in pyrolytic conversion of biomass [1-5]. The pyrolytic process has been pursued for commercial-scale production of fuel and chemicals [6-9]. An important aspect of carbohydrates pyrolysis (such as glucose, starch, and cellulose) is the formation of 1,6-anhydro- $\beta$-Dglucopyranose (levoglucosan, LG), as primary degradation product [10-12]. Levoglucosan can be utilized in the synthesis of chiral polymers such as non-hydrolysable glucose polymers and many new compounds [13-15]. Levoglucosan is often used as a chemical tracer for biomass burning in atmospheric chemistry studies [16-18], particularly with respect to airborne particulate matter. Unfortunately, as presently available, pure levoglucosan is very expensive because the yields of levoglucosan are very low. At the present price it is prohibited to use levoglucosan on a commercial scale.

Many studies have been reported on LG yields of 30-70\% from pure cellulose or starch [19-23]. Starch is generally used as the

\footnotetext{
* Corresponding author at: Department of Environmental and Municipal Engineering, Henan University of Urban Construction, Pingdingshan 46704, China. Tel.: +8610 62849155; fax: +8610 62923563.

** Corresponding author. Tel.: +86 10 62849155; fax: +861062923563.

E-mail addresses: yangzg1@126.com (Z. Yang), gqzhuang@rcees.ac.cn (G. Zhuang).
}

starting material for lab-scale levoglucosan preparation [10]. The high yields are obtained only in small-scale processes. However, for practical application, an efficient bigger-scale process is required. The factors that affect LG yield mainly are reaction temperature, residence time and heating rate [8]. In general, appropriate reaction temperature, short residence time and fast heating rate are advantage condition of producing levoglucosan $[8,39,40]$.

In our previous work on pyrolysis we find that a high vacuum degree is effective in capturing primary degradation products without secondary degradation [24-26]. High vacuum degree ensures that primary pyrolysis products quickly escape out of the reaction region and avoid secondary decomposition. Compared to other reactors, the tubular furnace pyrolysis reactor provides better performance under the pressure. Based on the above realization, we here develop a design of batch pyrolyzer. The pyrolyzer provides capabilities of scaling up for practical processes. Mechanism of lignocelluloses biomass thermodegradation has been discussed in many researches [27-35]. However, literatures regarding the changes in the physico-chemical of starch feedstock after a fast pyrolysis process are lacking. So the goals of this research are to investigate the effects of reaction temperatures and vacuum on products of starch pyrolysis and discuss a new possible pyrolysis mechanism.

\section{Experiments}

Fig. 1 shows the pyrolyzer schematically. It consists of four main parts: tubular furnace pyrolysis reactor, electrical heater, 


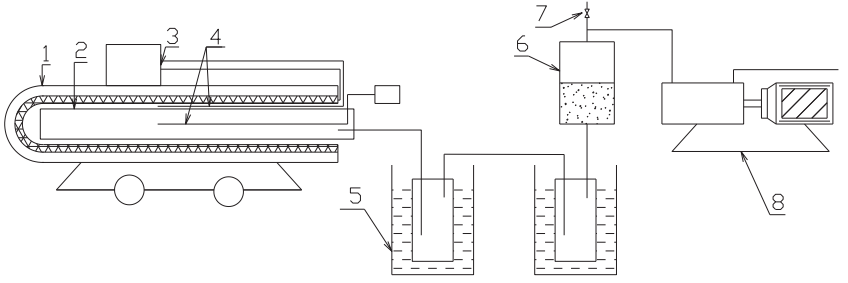

Fig. 1. Schematic diagram of the pyrolysis apparatus: (1) furnace; (2) stainless steel tubular reactor; (3) temperature controller; (4) thermocouple; (5) condenser; (6) filter and buffer; (7) valve; (8) vacuum pump.

temperature controller, condenser and vacuum system. The tubular furnace pyrolysis reactor is made of stainless steel tube with a length of $540 \mathrm{~mm}$ and inner diameter of $55 \mathrm{~mm}$. It has a volume of about $1.3 \mathrm{~L}$. The temperature at the center of the sample is measured by a thermocouple inside the reactor. The tubular furnace is controlled by an electric heater and a temperature controller. The outer side of the tube furnace is insulated with the glass wool $60 \mathrm{~mm}$ thick, which in turn is covered externally by steel $2 \mathrm{~mm}$ thick. Gases and vapors generated by the process are led to two ice-water condensers where products are collected. A specially designed gas inlet defends against liquid-like reactant from the inside out. Non-condensable gases are further depleted in a filter containing sawdust. The filter is also used as a buffer tank to increase the available vacuum volume. The reaction system is evacuated by a rotary pump with an ultimate pressure of $6 \times 10^{-2} \mathrm{~Pa}$ and a pumping speed of $15 \mathrm{~L} / \mathrm{s}$. Reactor is loaded with a batch of feedstock (500 g), sealed and evacuated, then inserted into the furnace (To facilitate the operation, furnace is movable and it is mounted on a wheeled vehicle). Samples are pyrolyzed at a series of oven temperatures in the range $360-420^{\circ} \mathrm{C}$. Condensable products are collected in an ice-water condenser situated between the pyrolysis oven and the filter. At desired reaction time (here is $40 \mathrm{~min}$ ), reactor is pulled out of the furnace and water-cooled and then after release of vacuum the residual is reweighed. The feedstock for pyrolysis is corn starch.

The pyrolysis sirup is quantitatively diluted with distilled water and analyzed by a HPLC system (GRE-3A Shimadzu) equipped with a Waters Model 401 refractive index detector and a Transgenomic ICSep ICEORH- 801 column $(300 \mathrm{~mm} \times 6.5 \mathrm{~mm})$, the injection volume is $10 \mathrm{~mL}$ and the column temperature is maintained at $48^{\circ} \mathrm{C}$. The eluent is $0.005 \mathrm{~mol} / \mathrm{L}$ sulfuric acid with flow rate of $0.6 \mathrm{~mL} / \mathrm{min}$. Levoglucosan is assayed by comparing the peak area for the sirup with that of levoglucosan from Sigma. According to literature-based knowledge [36-38] and our previous analysis [24], the HPLC peaks are labeled based on the identical retention time with the standard samples. Each experiment is repeated three times and the mean of them is used for the analysis.

Thermal analyses are made in a differential thermal balance (Beijing Henven Scientific Instument Factory, HCT-2) with a $\mathrm{N}_{2}$ flow of $50 \mathrm{~mL} / \mathrm{min}$ or an ultimate vacuum of $6 \times 10^{-2} \mathrm{~Pa}$. Samples are loaded into open alumina crucibles. The heating rates are $1-40 \mathrm{~K} / \mathrm{min}$. Samples weight is about $10 \mathrm{mg}$ in all cases, unless otherwise stated. At least two runs are performed for each sample in order to check the repeatability of measurements.

\section{Results and discussion}

\subsection{Heating rate of the sample}

Fig. 2 shows temperature measured at the center of reactor as a function of time for "final" pyrolysis temperature of $390^{\circ} \mathrm{C}$. Heating rate of the sample is about $50^{\circ} \mathrm{C}$ in the initial stage. For the temperature range $354-312^{\circ} \mathrm{C}$, the heating rate of the sample is

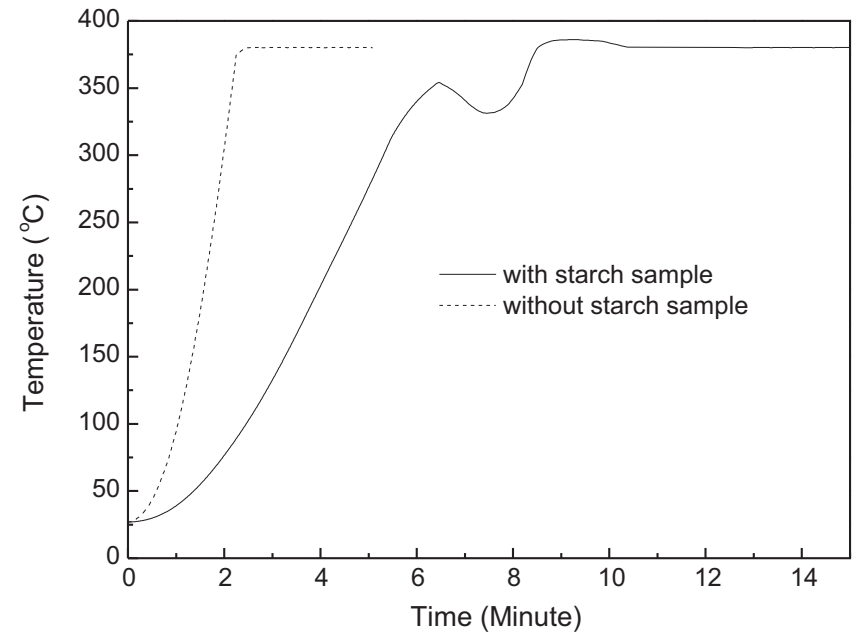

Fig. 2. Temperature of pyrolysis as measured by a thermocouple in starch sample or empty reactor. Final temperature is $390^{\circ} \mathrm{C}$.

directly related to the difference in the temperatures of the sample and oven. That is,

$\frac{d T}{d t}=k\left(T_{f}-T\right)$

where $T$ is the starch temperature at time $t\left(t_{0}=0\right.$ while $\left.T_{0}=312^{\circ} \mathrm{C}\right)$ and $k$ is a rate constant. Integration of (1) gives

$\ln \left[\frac{T_{f}-T_{0}}{T_{f}-T}\right]=k t$

where $T_{0}$ is the initial temperature. The value calculated for $k$ is $0.98 \mathrm{~min}^{-1}$ for the temperature range used in this investigation.

Thus,

$T=T_{f}-\left(T_{f}-T_{0}\right) e^{-0.98 t}$

Eq. (3) describes the temperatures in the reactor as a function of the time is a quantity in the exponent. It shows fast heating rate will be an important factor for the pyrolysis process. At temperatures in excess of $354^{\circ} \mathrm{C}$, the endothermic heat of pyrolysis results in pyrolysis temperatures lower than those predicted by Eq. (3) (see Fig. 2). After that it is found the exothermic heat of reaction resulted in pyrolysis temperatures a bit higher than $390^{\circ} \mathrm{C}$ (about $5^{\circ} \mathrm{C}$ ). Phase transition of reactant (from solid to liquid and from liquid to gas) and bond cleavage should contribute to the decrease of temperature. Whereas the exothermic heat means that exothermic reactions exist in the process of pyrolysis. And those exothermic reactions presumably are rearrangement reactions and violent free radical reactions. The phenomenon of exothermic heat is always observed during subsequent differential thermal process of starch. (In fact, the same phenomenon is also observed during thermal analyses of lignocellulosic biomass has been performed by us. It seems to be in contradiction to traditional idea of the endothermic heat of pyrolysis.)

\subsection{Preparation of levoglucosan}

Fig. 3 shows levoglucosan yield depends on both pyrolysis temperature and pressure. The levoglucosan yield is $28-56 \%$ under vacuum and $12-17 \%$ under nitrogen. The highest LG yield is $56.3 \%$ at vacuum and $390{ }^{\circ} \mathrm{C}, 16.7 \%$ at nitrogen and $390^{\circ} \mathrm{C}$. Correspondingly, char yields are $7.1 \%$ and $24.9 \%$; volatiles yields are $36.6 \%$ and $58.4 \%$. Under vacuum condition, levoglucosan highest yield of $40-70 \%$ from cellulose have been reported, e.g. $70.1 \%$ by Kwon et al. 

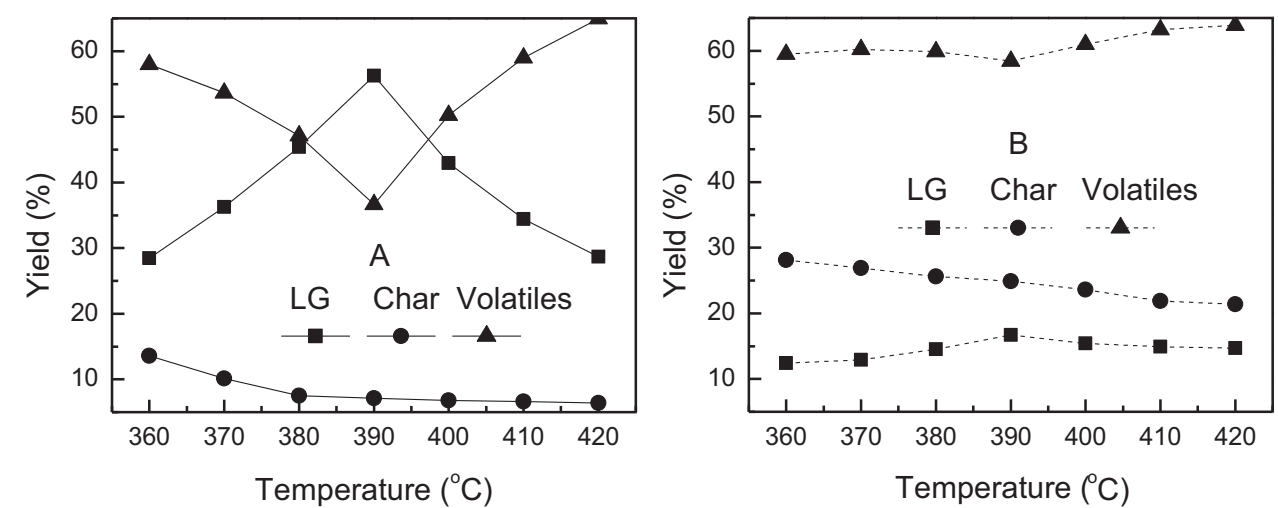

Fig. 3. Effect of temperature on pyrolysis product yields of corn starch. A for vacuum and B for atmospheric pressure. Yield of volatiles $=100-$ yields of LG and char.

[10], 58\% by Shafizadeh et al. [22] and 61\% by Essig et al. [23]. Vacuum leads to smaller char fractions (from 6\% to 14\%) whereas higher pressure (using a nitrogen flow at atmospheric pressure) leads to larger char fractions (from $21 \%$ to $28 \%$ ).

These indicate that higher vacuum is advantageous to produce levoglucosan. This is because higher vacuum reduce the residence time of LG in the sample during the pyrolysis reaction and accordingly secondary degradation is alleviated and product inhibition is mitigated. Under nitrogen, LG existing in sample should inhibit further formation of LG. Meanwhile as a reactant involved in subsequent reaction, the LG in sample leads to an increase in the yields of char and volatiles. (Note that the volatiles include condensable and non-condensable pyrolysis products except levoglucosan in this paper and its weight equals initial material minus char and LG).

As seen in Fig. 3, the weight of the residue becomes smaller as the reaction temperature is increased. However the decrease of char does not consistently match the yield of LG. This indicates the decrease of LG yield is not caused by secondary pyrolysis of LG because secondary pyrolysis of LG should produce more char. Moreover, higher vacuum is effective in capturing levoglucosan with little secondary degradation. Thus it can be inferred that LG and other volatile products is the result of two competing reactions instead of secondary reaction of LG. The inference serves as a basis of pyrolysis mechanism mentioned later.

Fig. 4 shows examples of chromatogram for the pyrolyzate. It gives that the major component of pyrolyzate from starch is levoglucosan. The levoglucosan content of sirup is about $70 \%$ at vacuum and $390^{\circ} \mathrm{C}$. This feature will be advantageous in

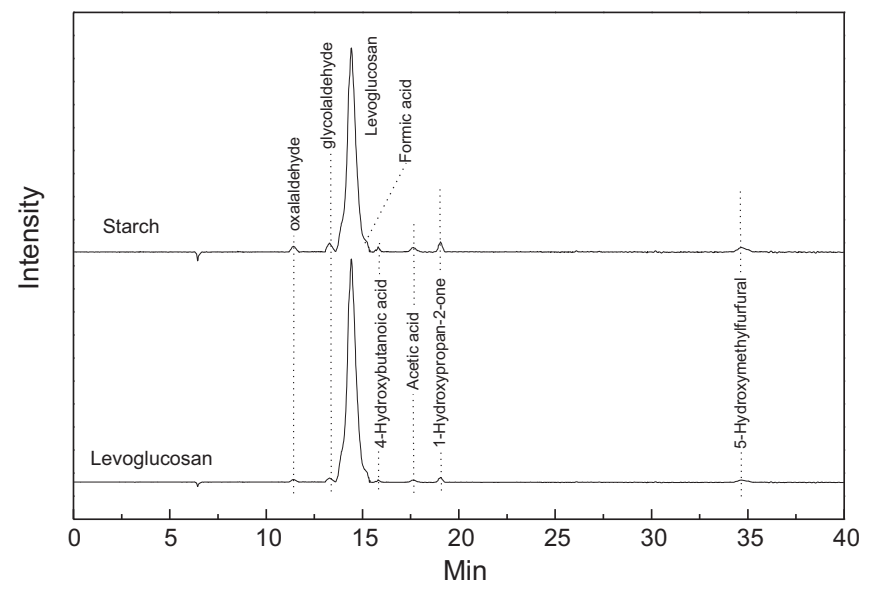

Fig. 4. HPLC chromatograms of the pyrolyzates of levoglucosan and corn starch at $390^{\circ} \mathrm{C}$. subsequent isolation/purification of levoglucosan from sirup. The minor components are respective oxalaldehyde, glycolaldehyde, formic acid, 4-hydroxybutanoic acid, acetic acid, hydroxyacetone, and 5-hydroxymethylfurfural, not identified, but based on the identical retention time with the standard samples.

\subsection{Pyrolysis of levoglucosan}

The result of LG pyrolysis shows char yield is lower than about $2 \%$ and recovery of $\mathrm{LG}$ is about $72 \%$ under conditions of vacuum and $390^{\circ} \mathrm{C}$. Pyrolysis of levoglucosan is known to give some residual char but little. The result indicates the vacuum helps fast evaporating of most levoglucosan molecules, but some of the molecules are converted into other products before evaporating. Note that thermal-degradation of LG before evaporating and evaporation is two competing processes. That is, thermal-degradation of LG cannot be simply seen as secondary reaction of LG but decomposition reaction before evaporating. And the reaction occurs in the process of solid-liquid and/or liquid-gas phase transition. However, LG formed gradually by corn starch pyrolysis is promptly evaporated out of reactor under high vacuum. So LG pyrolysis cannot be simply used to explain the process of corn starch pyrolysis. Although, Fig. 4 shows same condensable components from starch and LG which suggests that they undergo a similar reaction process.

The intermolecular hydrogen bonds exist in reactant during the pyrolysis process of carbohydrate. As a consequence, steric hindrance effect caused by intermolecular hydrogen bonds leads to

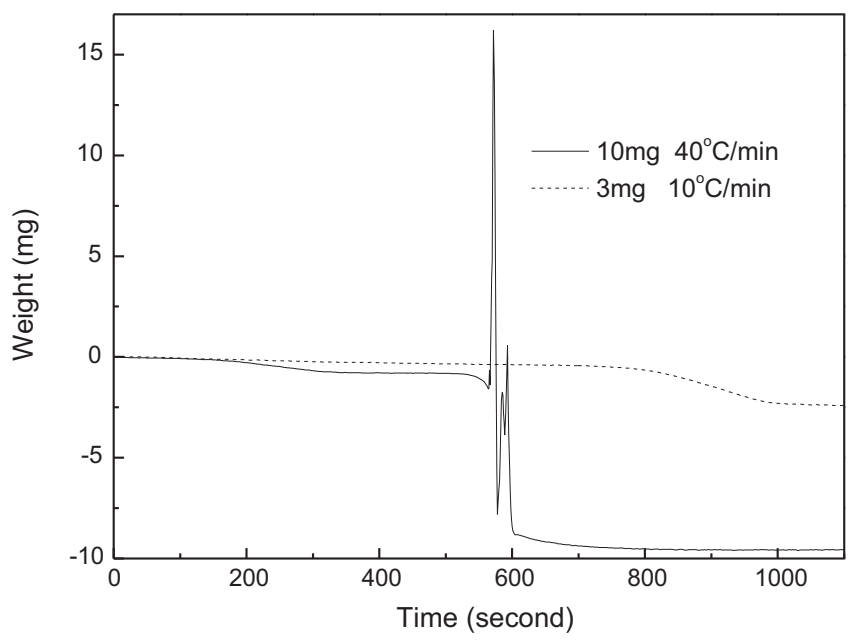

Fig. 5. TG curves of corn starch. 

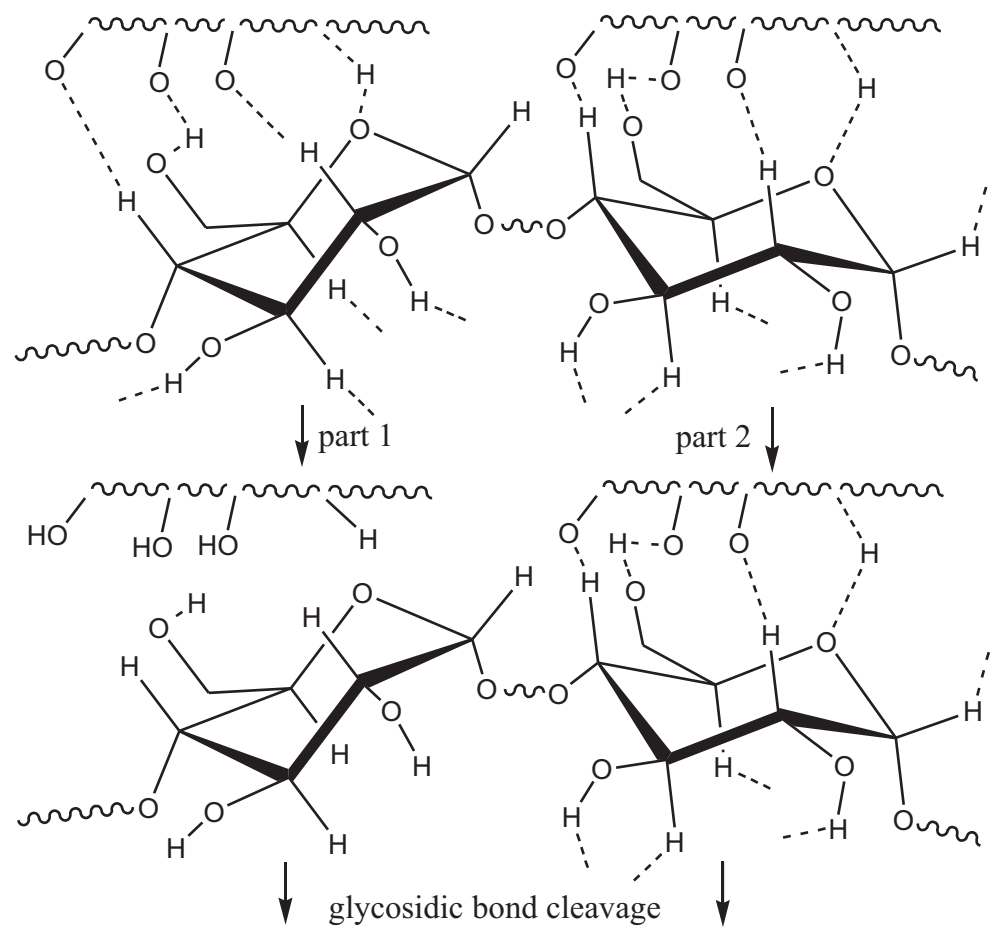

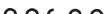

$\left.\mathrm{O}_{\mathrm{H} \rightarrow \mathrm{O}^{\mathrm{O}}}^{\mathrm{O}}\right|_{\mathrm{H}} ^{\mathrm{p}}$

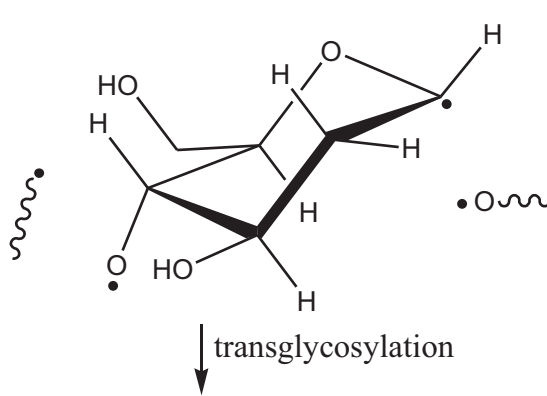

levoglucosan and residue

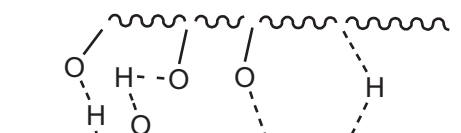

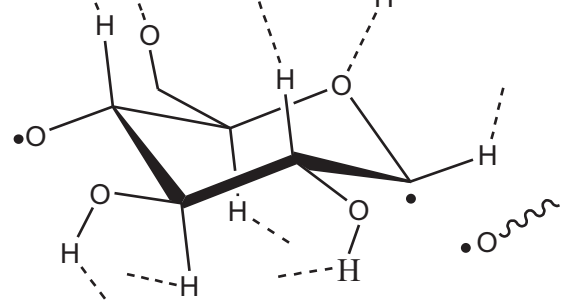

complicated radical reaction

residue and $\mathrm{H}_{2} \mathrm{O}+\mathrm{CO}+$ glycolaldehyde $+\cdots$
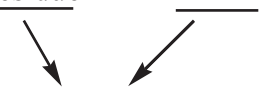

further thermo-degradation

Fig. 6. The thermal decomposition mechanism of starch.

complicated reactions which form volatiles except LG. The formation of these volatiles compete with the formation of LG. The competition affects the product distribution of the pyrolysis reaction.

\subsection{Thermal analysis}

The TG curves of the starting sample are shown in Fig. 5. A mass fluctuating phenomenon is observed in the process of thermogravimetric analysis. This phenomenon is always observed while changing sample weight and/or heating rate (Cumbersome experiments show that the phenomenon disappears when the mass is down to $3 \mathrm{mg}$ and heating rate down to $10 \mathrm{~K} / \mathrm{min}$ ). Opposite force caused by slight gas explosion is responsible for the mass fluctuation before they escape from the crucible. The gas explosion means violent free radical reaction during starch pyrolysis.

On the other hand, as seen in Fig. 5, the weight of the residue becomes smaller as the reaction time is increased. Since the intermediate residue at different times have the different properties (for example elements ratio and molecular structure), the residue at different reaction time cannot be simply regarded as a mixture of initial sample and final char but a particular reactant during pyrolysis.

Similar to the discussion before, DTA curve shows thermodegradation of corn starch undergoes the progress of first endothermic heat then exothermic heat. Endothermic heat should be attributed to phase transition and scission of glycosidic bonds whereas exothermic heat to rearrangement reactions and violent free radical reactions.

\subsection{Mechanism of thermo-degradation}

Since levoglucosan is a main product and previous residue is following reactant, starch degradation can be assumed that two competing first-order reactions occur via intermediate residue to yield (1) levoglucosan, (2) other fraction, here termed "volatiles" 
which includes condensable fraction (such as water, oxalaldehyde, glycolaldehyde, formic acid, 4-hydroxybutanoic acid, acetic acid, etc.) and non-condensable fraction (such as carbon dioxide, methane, carbon monoxide, hydrogen, etc.):

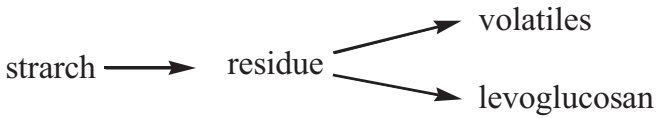

This mechanism is significantly different from the traditional Broido-Shafizadeh model [28]:

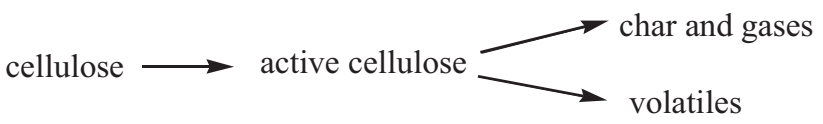

To clearly elucidate the mechanism of thermo-degradation, Fig. 6 shows the process of thermal decomposition. According to this scheme, both steps presumably are connected firstly with a scission of glycosidic bonds, namely the primary formation of the glycosidic radicals. The primary formation of the radicals subsequently leads either to the direct formation of levoglucosan by transglycosylation or to the formation of residue and volatiles by complicated radical reactions. The selectivity is controlled by depolymerization or polymerization, which caused by hydrogen bonding between glycosidic radicals and surrounding molecules (or fragments) in the liquid-like residue. Intermolecular hydrogen bonding inhibits the direct transglycosylation of the ether ring. The reaction of depolymerization is the primary path which forms levoglucosan. The steric hindrance caused by polymerization is the main factor for pyrolysis product distribution. Reference [41] states the similar effects occur in the pyrolysis process of cellulose biomass, but its polymerization is mainly caused by the crosslinking between the polysaccharides (cellulose and hemicellulose) and the lignin via ester and ether linkages. Fast heating rate plays the role of the promoter of this process accelerating it by the radical mechanism.

The effects of glycosidic radical on the surrounding molecule units depend on their intermolecular hydrogen bonds and crosslinking. The glycosidic radicals with free space directly form levogucosan molecule (as part 1 of Fig. 6 shows). On the contrary, other glycosidic radicals are converted into residue and other volatiles by complicated radical reactions (as part 2 of Fig. 6 shows). The yields of LG and volatiles depend on the ratio of part 1 to part 2. In other words, it is more about increasing the ratio of part 1 to part 2 to obtain higher yield of LG. Higher vacuum and appropriate temperature make it profitable to increase the ratio. Temperature also has an important influence on rates of conversion of LG and volatiles. So a desired temperature obtained by experiment is necessary to maximize yield of LG. Higher temperature leads to more violent free radical reaction and longer reaction time improves the extend of reaction which explains yield of char gradually decreases with the increase of temperature or reaction time.

\section{Conclusion}

Tubular furnace pyrolysis reactor for the production of levoglucosan from biomass has been demonstrated at a pilot-scale of $500 \mathrm{~g} / \mathrm{batch}$. The maximum yield of levoglucosan from corn starch is about $56 \%$ (analytical value) at vacuum and $390^{\circ} \mathrm{C}$. Thus the practice of our method is proved effective in maximizing levoglucosan product. Based on our work, another plate-reaction pyrolysis system is further designed for an industrial scale production of high-yield levoglucosan from biomass pyrolysis and levoglucosan of $1 \mathrm{~kg}$ is achieved each batch. The technology has been commercially transferred to a company.
This investigation provides a new pyrolysis mechanism of biomass. Starch macromolecules are not directly converted to low molecular weight volatile products, char and LG, but undergo intermediate physical and chemical changes including a crystal hydrogen elimination, transglycosylation and glycoside-derived free radical reaction. These changes are responsible for the activation of the macromolecules before they undergo rapid thermal degradation. It is generally concluded that two competing first-order reactions occur via intermediate residue to yield Levoglucosan and other volatiles during the process of starch pyrolysis.

\section{Acknowledgments}

This work was financially supported by National Natural Science Foundation of China (No. 21177153) and the Key Programs of the Chinese Academy of Sciences (No. KZZD-EW-09-3).

\section{References}

[1] A. Pattiya, S. Suttibak, Production of bio-oil via fast pyrolysis of agricultural residues from cassava plantations in a fluidised-bed reactor with a hot vapour filtration unit, Journal of Analytical and Applied Pyrolysis 95 (2012) 227.

[2] Z. Jiang, Z. Liu, B. Fei, Z. Cai, Y. Yu, X. Liu, The pyrolysis characteristics of moso bamboo original research article, Journal of Analytical and Applied Pyrolysis 94 (2012) 48.

[3] T. Imam, S. Capareda, Characterization of bio-oil, syn-gas and bio-char from switchgrass pyrolysis at various temperatures, Journal of Analytical and Applied Pyrolysis 93 (2012) 170.

[4] S. Ren, H. Lei, L. Wang, Q. Bu, S. Chen, J. Wu, J. Julson, R. Ruan, Biofuel production and kinetics analysis for microwave pyrolysis of Douglas fir sawdust pellet, Journal of Analytical and Applied Pyrolysis 94 (2012) 163.

[5] P. Fu, S. Hu, J. Xiang, L. Sun, S. Su, S. An, Study on the gas evolution and char structural change during pyrolysis of cotton stalk, Journal of Analytical and Applied Pyrolysis 97 (2012) 130.

[6] D.S. Scott, J. Piskorz, The continuous flash pyrolysis of biomass, Canadian Journal of Chemical Engineering 62 (1984) 404.

[7] J. Piskorz, D. Radlein, D.S. Scott, S. Czernik, Pretreatment of wood and cellulose for production of sugars by fast pyrolysis, Journal of Analytical and Applied Pyrolysis 16 (1989) 127.

[8] D. Radlein, J. Piskorz, D.S. Scott, Fast pyrolysis of natural polysaccharides as a potential industrial process, Journal of Analytical and Applied Pyrolysis 19 (1991) 41.

[9] Z. Yang, H. Kang, Y. Guo, Y. Dong, C. Feng, G. Zhuang, Z. Bai, H. Zhang, Dilute-acid conversion of cotton straw to sugars and levulinic acid via 2-stage hydrolysis, Industrial Crops and Products 46 (2013) 205.

[10] G.-J. Kwon, D.-Y. Kim, S. Kimura, S. Kuga, Rapid-cooling, continuous-feed pyrolyzer for biomass processing: Preparation of levoglucosan from cellulose and starch, Journal of Analytical and Applied Pyrolysis 80 (2007) 1.

[11] M. Sasaki, K. Takahashi, Y. Haneda, H. Satoh, A. Sasaki, A. Narumi, T. Satoh, T. Kakuchi, H. Kag, Thermochemical transformation of glucose to 1,6-anhydroglucose in high-temperature steam, Carbohydrate Research 343 (2008) 848.

[12] C.M. Lakshmanan, H.E. Hoelscher, Production of levoglucosan by pyrolysis of carbohydrates. Pyrolysis in hot inert gas stream, Industrial \& Engineering Chemistry Product Research Development 9 (1970) 57.

[13] K. Krohn, D. Gehle, U. Flörke, New derivatives of levoglucosan by tandem epoxide allyl alcohol rearrangement-cuprate cross-coupling, European Journal of Organic Chemistry 13 (2005) 2841.

[14] N.M. Merlis, E.A. Andrievskaya, L.I. Kostelian, O.P. Golova, Synthesis of desoxy derivatives of $\beta$-1, 6-anhydro-D-glucopyranose (levoglucosan), Bulletin of the Academy of Sciences of the USSR. Division of Chemical Science 24 (1975) 128.

[15] V. Bailliez, A. Olesker, J. Cleophax, Synthesis of polynitrogenated analogues of glucopyranoses from levoglucosan, Tetrahedron 60 (2004) 1079.

[16] C. Piot, J.-L. Jaffrezo, J. Cozic, N. Pissot, I. El Haddad, N. Marchand, J.-L. Besombes, Quantification of levoglucosan and its isomers by high performance liquid chromatography-electrospray ionization tandem mass spectrometry and its applications to atmospheric and soil samples, Atmospheric Measurement Techniques 5 (2012) 141.

[17] M. Giannoni, T. Martellini, M. Del Bubba, A. Gambaro, R. Zangrando, M. Chiari, L. Lepri, A. Cincinelli, The use of levoglucosan for tracing biomass burning in $\mathrm{PM}_{2.5}$ samples in Tuscany (Italy), Environmental Pollution 167 (2012) 7.

[18] E.C. Rada, M. Ragazzi, E. Malloci, Role of levoglucosan as a tracer of wood combustion in an alpine region, Environmental Technology 33 (2012) 989.

[19] D. Gardiner, The pyrolysis of some hexoses and derived di-, tri-, and polysaccharides, Journal of the Chemical Society C 0 (1966) 1473.

[20] F. Shafizadeh, Pyrolysis and combustion of cellulosic materials, Advances in Carbohydrate Chemistry 23 (1968) 419.

[21] M. Černý, J. Staněk, 1,6-Anhydro derivatives of aldohexoses, Advances in Carbohydrate Chemistry and Biochemistry 34 (1977) 23. 
[22] F. Shafizadeh, R.H. Furneaux, T.G. Cochran, J.P. Scholl, Y. Sakai, Production of levoglucosan and glucose from pyrolysis of cellulosic materials, Journal of Applied Polymer Science 23 (1979) 3525.

[23] M. Essig, G.N. Richards, E. Schenck, in: C. Schuerch (Ed.), Mechanism of Formation of the Major Volatile Products from the Pyrolysis of Cellulose. Cellulose and Wood-Chemistry and Technology, Wiley Interscience, New York, 1989, p. 841.

[24] Z. Yang, B. Zhang, X. Chen, Z. Bai, H. Zhang, Studies on pyrolysis of wheat straw residues from ethanol production by solid-state fermentation, Journal of Analytical and Applied Pyrolysis 81 (2008) 243.

[25] L. Li, H. Zhang, X. Zhuang, Pyrolysis of waste paper: characterization and composition of pyrolysis oil, Energy Source 27 (2005) 867.

[26] X.L. Zhuang, H.X. Zhang, J.Z. Yang, H.Y. Qi, Preparation of levoglucosan by pyrolysis of cellulose and its citric acid fermentation, Bioresource Technology 79 (2001) 63.

[27] J. Lédé, Cellulose pyrolysis kinetics: an historical review on the existence and role of intermediate active cellulose, Journal of Analytical and Applied Pyrolysis 94 (2012) 17.

[28] G.W.A. Bradbury, Y. Sakai, F. Shafizadeh, A kinetic model for pyrolysis of cellulose, Journal of Applied Polymer Science 23 (1979) 3271.

[29] V. Mamleev, S. Bourbigot, J. Yvon, Kinetic analysis of the thermal decomposition of cellulose: the main step of mass loss, Journal of Analytical and Applied Pyrolysis 80 (2007) 151.

[30] V. Mamleev, S. Bourbigot, J. Yvon, Kinetic analysis of the thermal decomposition of cellulose: the change of the rate limitation, Journal of Analytical and Applied Pyrolysis 80 (2007) 141.

[31] C.D. Blasi, Comparison of semi-global mechanisms for primary pyrolysis of lignocellulosic fuels, Journal of Analytical and Applied Pyrolysis 47 (1998) 43.
[32] R.K. Agrawal, Kinetics of reactions involved in pvrolvsis of cellulose II. The modified kilzer-bioid model, Canadian Journal of Chemical Engineering 66 (1988) 413.

[33] A.G.W. Bradbury, Y. Sakai, F. Shafizadeh, A kinetic model for pyrolysis of cellulose, Journal of Applied Polymer Science 23 (1979) 3271.

[34] G. Varhegyi, E. Jakab, M.J. Antal, Is the Broido-Shafizadeh model for cellulose pyrolysis true? Energy Fuel 8 (1994) 1345.

[35] W. Chaiwat, I. Hasegawa, T. Tani, K. Sunagawa, K. Mae, Analysis of cross-linking behavior during pyrolysis of cellulose for elucidating reaction pathway, Energy Fuel 23 (2009) 5765

[36] X. Wei, Q. Lu, X. Sui, Z. Wang, Y. Zhang, Characterization of the water-insoluble pyrolytic cellulose from cellulose pyrolysis oil, Journal of Analytical and Applied Pyrolysis 97 (2012) 49.

[37] H. Kawamoto, H. Morisaki, S. Saka, Secondary decomposition of levoglucosan in pyrolytic production from cellulosic biomass, Journal of Analytical and Applied Pyrolysis 85 (2009) 247.

[38] G.N. Richards, Glycolaldehyde from pyrolysis of cellulose, Journal of Analytical and Applied Pyrolysis 10 (1987) 251.

[39] X. Bai, P. Johnston, R.C. Brown, An experimental study of the competing processes of evaporation and polymerization of levoglucosan in cellulose pyrolysis, Journal of Analytical and Applied Pyrolysis 99 (2013) 130.

[40] F. Ronsse, D. Dalluge, W. Prins, R.C. Brown, Optimization of platinum filament micropyrolyzer for studying primary decomposition in cellulose pyrolysis, Journal of Analytical and Applied Pyrolysis 95 (2012) 247.

[41] P.R. Patwardhan, J.A. Satrio, R.C. Brown, B.H. Shanks, Product distribution from fast pyrolysis of glucose-based carbohydrates, Journal of Analytical and Applied Pyrolysis 86 (2009) 323. 